\title{
A concurrent Dual-band CMOS low noise amplifier at 2.4/5.2 GHz for WLAN applications
}

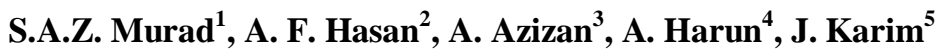 \\ ${ }^{1,4}$ School of Microelectronic Engineering, Universiti Malaysia Perlis, Malaysia \\ ${ }^{2,3}$ Department of Electronic Engineering, Faculty of Engineering Technology, Universiti Malaysia Perlis, Malaysia \\ ${ }^{5}$ Electrical Engineering Faculty, University Teknologi MARA, Malaysia
}

\begin{tabular}{l} 
Article Info \\
\hline Article history: \\
Received Sep 27, 2018 \\
Revised Nov 26, 2018 \\
Accepted Jan 27, 2019 \\
\hline Keywords: \\
Cascode \\
CMOS \\
Dual-ferquencies \\
Low noise amplifier \\
WLAN \\
\hline
\end{tabular}

\begin{abstract}
This paper presents a concurrent dual-band CMOS low noise amplifier (LNA) at operating frequency of $2.4 \mathrm{GHz}$ and $5.2 \mathrm{GHz}$ for WLAN applications. The proposed LNA employed cascode common source to obtain high gain using $0.13-\mu \mathrm{m}$ CMOS technology. The concurrent dualband frequencies are matched using LC network band-pass and band-stop notch filter at the input and output stages. The filters help to shape the frequency response of the proposed LNA. The simulation results indicate that the LNA achieves a forward gain of $21.8 \mathrm{~dB}$ and $14.22 \mathrm{~dB}$, input return loss of $-18 \mathrm{~dB}$ and $-14 \mathrm{~dB}$ at $2.4 \mathrm{GHz}$ and $5.2 \mathrm{GHz}$, respectively. The noise figure of $4.1 \mathrm{~dB}$ and $3.5 \mathrm{~dB}$ with the input third-order intercept points $7 \mathrm{dBm}$ and 10 $\mathrm{dBm}$ are obtained at $2.4 \mathrm{GHz}$ and $5.2 \mathrm{GHz}$, respectively. The LNA dissipates $2.4 \mathrm{~mW}$ power at $1.2 \mathrm{~V}$ supply voltage with a chip size of $1.69 \mathrm{~mm} 2$.
\end{abstract}

Copyright $\left({ }_{0} 2019\right.$ Institute of Advanced Engineering and Science. All rights reserved.

\section{Corresponding Author:}

Sohiful Anuar Zainol Murad, School of Microelectronic Engineering,

Universiti Malaysia Perlis,

Pauh Putra Campus, 02600 Arau, Perlis, Malaysia.

Email: sohiful@unimap.edu.my

\section{INTRODUCTION}

Wireless Local Access Network or WLAN has been used tremendously nowadays with various technologies that mounted rapidly. In order to transmit and receive data, wireless LAN uses radio frequency signal, infrared or microwave as medium of transmission without using cables [1]. Whenever a transmitter or an antenna transmit RF signal to the receiver, the signal becomes weak and have high possibility to contaminate with noise from surrounding [2]. Thus, a successful amplifier is needed to amplify the signal and decreasing the noise significantly. This leads to the design of LNA or Low Noise Amplifier. The LNA amplifiers which indeed a low noise and it is appropriate compared to other receiver due to its high selectivity and contain more sensitivity via a narrow-band at just one input frequency [3-4]. In previous proposed LNA project, the implementation on single-band frequencies is reported to reach gain and matching at single band frequencies of interest. However, the needs to have an effective dual-band receiver in RF communication system are crucial because it increase the usability of the LNA for those WLAN applications. Furthermore, the concurrent dual-band topology will utilize the characteristic of wideband in CMOS [5].

The key to achieve dual-band characteristics is by dual-band concurrent technique which allows the matching simultaneously without any switching operation [6]. The switching technique will leads to unnecessary increase in area and cost [7]. In the case of LNA, noise figure are a vital consideration as the LNA receives a very weak input signal [8]. While the LNA is an active block in receiving chain, the noise figure sets at the LNA stages are the minimum value of noise at the entire system. This is due to the noise in each stage will decrease as the gain is increased. Another circumstances involved in designing the low noise amplifier which are the gain that can be produced in entire LNA design [9]. For the number of MOS 
transistor used in this design, the internal gain that can possibly be produced by each stages must be enough to contribute a strong signal with adequate gain at the output [10]. Thus, a cascode stages are implemented to improve the entire LNA gain.

\section{DESIGN IMPLEMENTATION}

Figure 1 shows the proposed dual band LNA using CMOS $0.13-\mu \mathrm{m}$ technology. The LNA is implemented using a cascode CMOS stages with a combination of a common-source (CS) and a commongate (CG) transistor. One of the main advantages of cascode topology is high gain and better reverse isolation. Each gate of the transistor is biased with a $5 \mathrm{k} \Omega$ resistor for $\mathrm{R} 1$ and $\mathrm{R} 2$. The function of resistor is to control the current flow from the DC voltage of $\mathrm{Vg} 1$ and $\mathrm{Vg}$ 2. The current flowing through each of the transistor is the minimum value of current and hence the transistor can be protected from high current. A bypass capacitor is added at the input and output terminal to block dc sources and bypass ac sources [11]. Capacitor C3 is added to the gate of transistor M2 in order to provide an ac ground. This simply means that an ac signal which passes through the capacitor $\mathrm{C} 3$ is to be grounded. Therefore, no current will flow via an AC ground. In order to enhance the gain of LNA, inductor L3 is added at the gate of common gate transistor. A small signal equivalent circuit of $C G$ transistor and $L_{3}$ is illustrated in Figure 2.

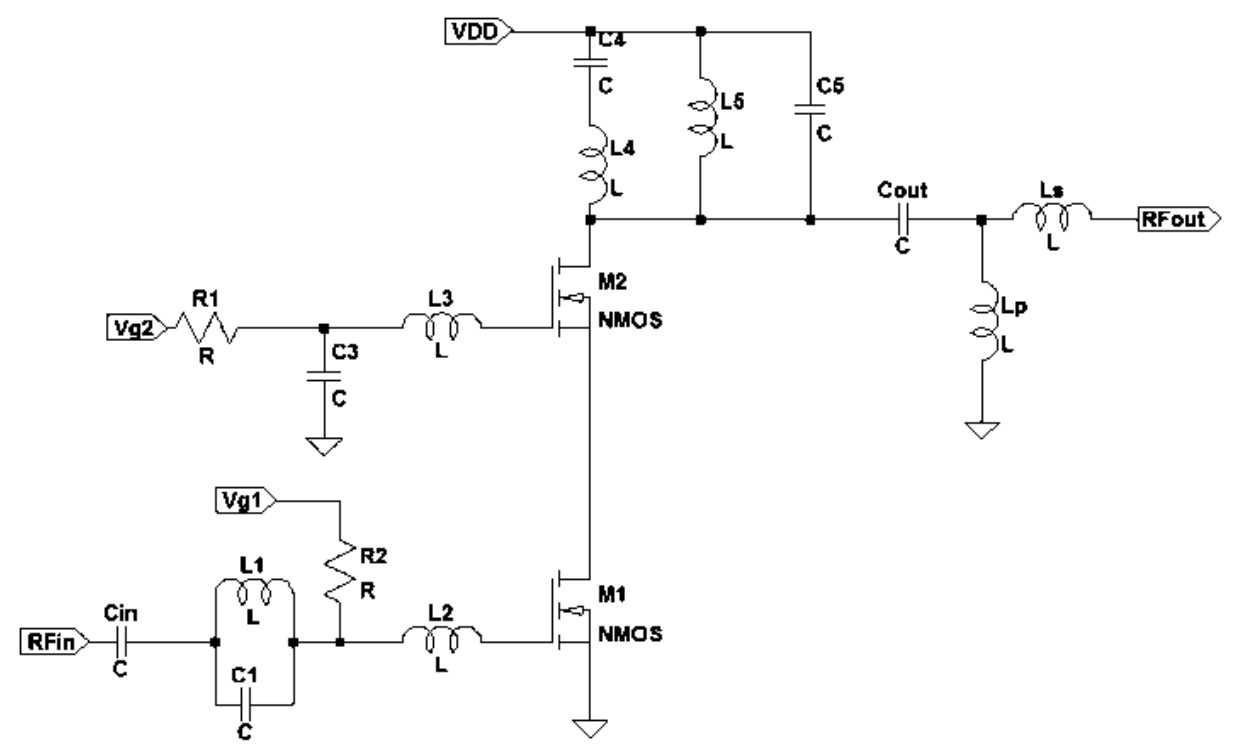

Figure 1. The proposed dual band LNA for $2.4 \mathrm{GHz}$ and $5.2 \mathrm{GHz}$

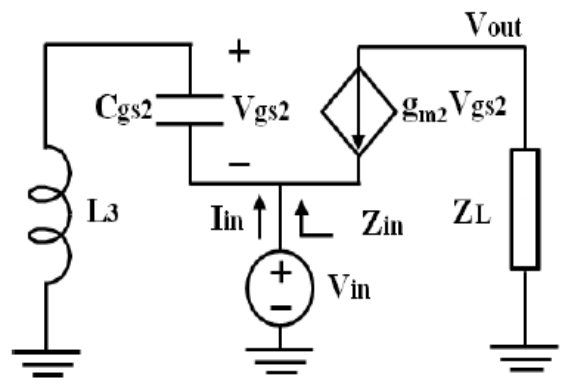

Figure 2. A small signal equivalent circuit of CG transistor and L3

Based on the equivalent circuit in Figure 2, the gate to drain capacitance $C_{g d 2}$ are neglected. Thus, $\mathrm{V}_{\mathrm{gs} 2}$ can be expressed as follows: 


$$
V_{g s 2}=\frac{-\left(\frac{1}{j \omega C_{g s 2}}\right) V_{i n}}{\left(\frac{1}{j \omega C_{g s 2}}\right)+j \omega L_{3}}=\frac{-V_{i n}}{1-\omega^{2} L_{3} C_{g s 2}}
$$

The $\mathrm{C}_{\mathrm{gs} 2}$ and $\omega$ are the capacitance of gate to source and the operating frequencies of M2, respectively. Referred to (1), the amplitude of gate to source voltage $\left(\mathrm{V}_{\mathrm{gs} 2}\right)$ of transistor $\mathrm{M} 2$ will be increased if $\left|1-\omega^{2} L_{3} C_{g s}\right|$ is less than 1 . As a result, the transconductance of $M 2$ are improved uniformly which leads to enhancement of the gain of LNA. However, the improvement of the gain is restricted with value inductor $\mathrm{L}_{3}$. If the value is larger, it will contribute to non-stability of the LNA circuit which includes the negative resistance at the common gate transistor. The reason can be shown by deriving $I_{\text {in }}$ and $Z_{\text {in }}$ which is the input current and input impedance respectively at the M1 transistor as follows:

$$
\begin{gathered}
I_{i n}=\frac{V_{i n}}{\frac{1}{j \omega C_{g s 2}}+j \omega L_{3}}+\frac{g_{m 2}\left(\frac{1}{j \omega C_{g s 2}}\right) V_{i n}}{\frac{1}{j \omega C_{g s 2}}+j \omega L_{3}} \\
Z_{i n}=\frac{V_{i n}}{I_{i n}}=\frac{1}{g_{m 2}+j \omega C_{g s 2}} \times\left(1-\omega^{2} L_{3} C_{g s 2}\right)
\end{gathered}
$$

Another important feature in this LNA design is the absence of inductive source degeneration at the common source of M1. The inductive source degeneration will degenerate the gain of LNA. However, this could leads to linearity distortion and low quality noise figure [12]. The operation of matching networks at input and output of dual-band LNA is accomplished by concurrent technique instead of switching technique. This is due to the concurrent technique allows matching operation simultaneously. Hence, it consumes less power and reducing the chip area. Typically, one of the important factors that reduce the gain of LNA is the low Quality Factor (Q-factor) of CMOS inductor in matching network. Therefore, the cascode topology is implemented to overcome this problem especially at microwave or millimeter wave frequencies.

The input and output frequency response is developed from bandpass and band stop filter networks. Figure 3 shows the gain frequencies response of dual band LNA. The operating frequencies of LNA are $\omega_{1}$ and $\omega_{2}$ for $2.4 \mathrm{GHz}$ and $5.2 \mathrm{GHz}$ respectively while the notch filter frequencies for input and output matching are as $\omega_{3}$ and $\omega_{4}$.

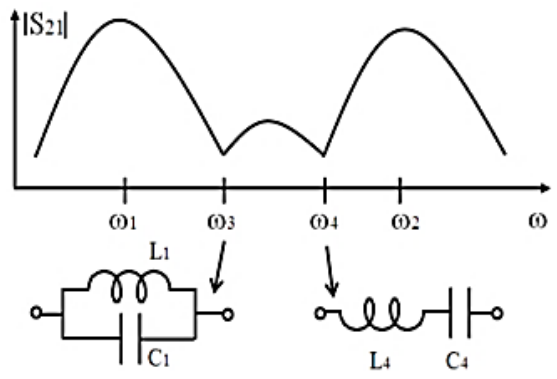

Figure 3. Frequency response of bandpass and band stop filter networks

For the input matching, the equation shows the relationship between notch frequency and resonator of $\mathrm{L} 1$ and $\mathrm{C} 1$ is given by:

$$
L_{4} C_{4}=\frac{1}{\omega_{4}^{2}}
$$

The matching network of the input stage is realized by resonator of L2 and also transconductance of $\mathrm{M} 1\left(\mathrm{C}_{\mathrm{gs} 1}\right)$. At $\omega_{1}$ of $2.4 \mathrm{GHz}$ frequency, $\mathrm{L}_{2}$ are function as inductive while $\mathrm{C}_{\mathrm{gs} 1}$ are capacitive. On the other 
hand, at frequency $\omega_{2}$ of $5.2 \mathrm{GHz}, \mathrm{L}_{2}$ and $\mathrm{C}_{\mathrm{gs} 1}$ are capacitive and inductive, respectively. This will cancelled the imaginary part of input impedance, $Z_{\mathrm{in}}$. Therefore, the value of $\mathrm{C}_{\mathrm{gs}}$ is decided while the value of inductor $\mathrm{L}_{1}, \mathrm{~L}_{2}$ and capacitance $\mathrm{C} 1$ are obtain as follows:

$$
\begin{aligned}
& \frac{\omega_{3}^{2} L_{1}}{\omega_{3}^{2}-\omega_{1}^{2}}=\frac{1}{\omega_{3}^{2} C_{g s 1}}-L_{2} \\
& \frac{\omega_{3}^{2} L_{1}}{\omega_{3}^{2}-\omega_{3}^{2}}=L_{2}-\frac{1}{\omega_{3}^{2} C_{g s 1}}
\end{aligned}
$$

For the output matching stage, the relationship between notch frequency of $\omega_{4}$ and resonator that consist of inductor L4 and capacitor C4 is expressed as follows:

$$
L_{4} C_{4}=\frac{1}{\omega_{4}^{2}}
$$
follows:

The resonator is capacitive at $\omega_{1}$ while it is inductive at $\omega_{2}$. This condition can be expressed as

$$
\begin{aligned}
& L_{5}\left(C_{5}+C_{p}\right)=\frac{1}{\omega_{1}^{2}} \\
& \frac{L_{5} L_{p}}{L_{5}+L_{p}} C_{5}=\frac{1}{\omega_{2}^{2}}
\end{aligned}
$$

Where $\mathrm{C}_{\mathrm{p}}$ and $\mathrm{L}_{\mathrm{p}}$ is expressed as:

\begin{tabular}{|c|c|c|c|}
\hline Parameters & Design Value & Parameters & Design Value \\
\hline M1 & $\begin{array}{c}172.2 \mu \mathrm{m} / 0.13 \\
\mu \mathrm{m}\end{array}$ & M2 & $\begin{array}{l}220 \mu \mathrm{m} / \\
0.13 \mu \mathrm{m}\end{array}$ \\
\hline L1 & $3.5 \mathrm{nH}$ & $\mathrm{C} 1$ & $0.88 \mathrm{pF}$ \\
\hline L2 & $4.5 \mathrm{nH}$ & $\mathrm{R} 1$ & $680 \Omega$ \\
\hline L3 & $0.93 \mathrm{nH}$ & C3 & $1.04 \mathrm{pF}$ \\
\hline $\mathrm{L} 4$ & $3.9 \mathrm{nH}$ & $\mathrm{C} 4$ & $0.26 \mathrm{pF}$ \\
\hline L5 & $0.98 \mathrm{nH}$ & C5 & $1.96 \mathrm{pF}$ \\
\hline Cin $=$ Cout & $1.0 \mathrm{pF}$ & R2 & $5.9 \mathrm{k} \Omega$ \\
\hline $\mathrm{L}_{\text {SERIES }}$ & $0.56 \mathrm{nH}$ & LPARALLEL & $2.24 \mathrm{nH}$ \\
\hline
\end{tabular}

$$
C_{p}=\frac{\omega_{4}^{2} C_{4}}{\omega_{4}^{2}-\omega_{1}^{2}}, L_{p}=\frac{\omega_{2}^{2}-\omega_{4}^{2}}{\omega_{4}^{2} \omega_{2}^{2} C_{4}}
$$

The component parameters including biasing, supply voltage, transistors size, inductors, capacitors and resistors for the proposed dual-band LNA is tabulated in Table 1.

Table 1. Component Parameters for Concurrent Dual-Band 2.4/5.2 GHz LNA

\section{RESULTS}

The proposed design of dual-band LNA is simulated using Cadence SpectreRF simulator at $2.4 \mathrm{GHz}$ and $5.2 \mathrm{GHz}$ in Silterra $0.13-\mu \mathrm{m}$ technology. The proposed LNA dissipates a total current of $27.4 \mathrm{~mA}$ from $1.2 \mathrm{~V}$ supply voltage. Figure 4 shows the simulated result of forward gain S21. The proposed LNA obtains gain of $21.9 \mathrm{~dB}$ and $14.2 \mathrm{~dB}$ at $2.4 \mathrm{GHz}$ and $5.2 \mathrm{GHz}$, respectively. The notch frequencies which realized by the bandpass and bandstop filters are $3 \mathrm{GHz}$ and $4.7 \mathrm{GHz}$, respectively. The gain obtained by the LNA proves that the input and output impedance achieve a maximum power gain transfer and the realization of bandpass and bandstop notch filter can produce a stable peak gain at operating frequency of $2.4 \mathrm{GHz}$ and 5.2 $\mathrm{GHz}$. The gain response also describe the highest gain is achieved at $2.4 \mathrm{GHz}$ compared to $5.2 \mathrm{GHz}$. This is 
due to the presence of inductor L3 at the input of common-gate transistor. The higher value of inductance will limit the gain response of LNA.

The simulated input return loss S11 and output return loss S22 are depicted in Figure 5. The input return loss of $-18 \mathrm{~dB}$ and $-16 \mathrm{~dB}$ are achieved at $2.4 \mathrm{GHz}$ and $5.2 \mathrm{GHz}$, respectively. Meanwhile, the output return loss of $-14 \mathrm{~dB}$ at $2.4 \mathrm{GHz}$ and $-15.8 \mathrm{~dB}$ at $5.2 \mathrm{GHz}$ are obtained.

Figure 6 shows the noise figure (NF) simulated result of the proposed LNA. As can be seen, the NFs are $4.1 \mathrm{~dB}$ and $3.5 \mathrm{~dB}$ at $2.4 \mathrm{GHz}$ and $5.2 \mathrm{GHz}$, respectively. The basic requirement of noise figure for the common LNA design is $3 \mathrm{~dB}$. Since the LNA is designed by a power matching over a noise matching, it shows that the proposed LNA contribute slightly high in noise compared to design specification. The main reason of the noise contribution by the LNA is due to the high value of inductors use in the proposed design.

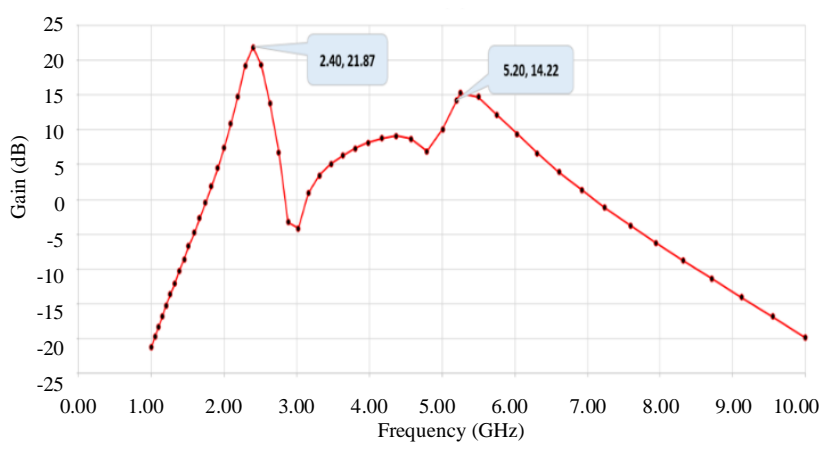

Figure 4. Simulation result of S21

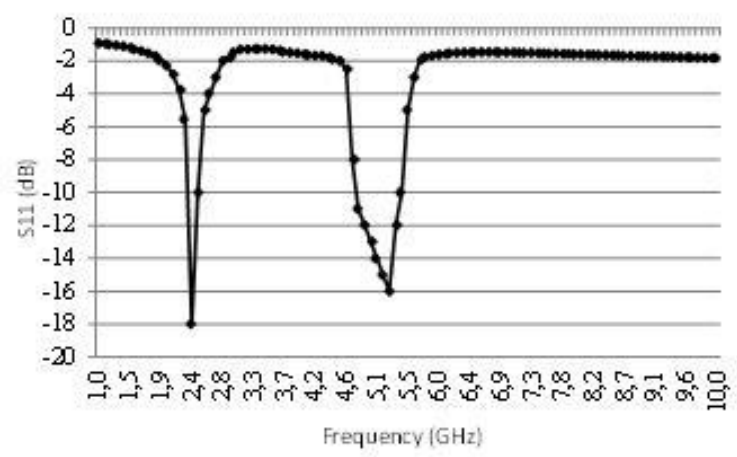

(a)

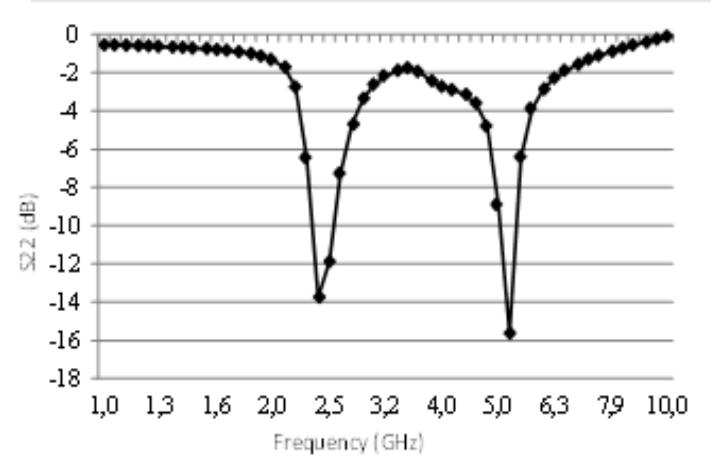

(b)

Figure 5. Input and output return loss simulation results: (a) S11, (b) S22

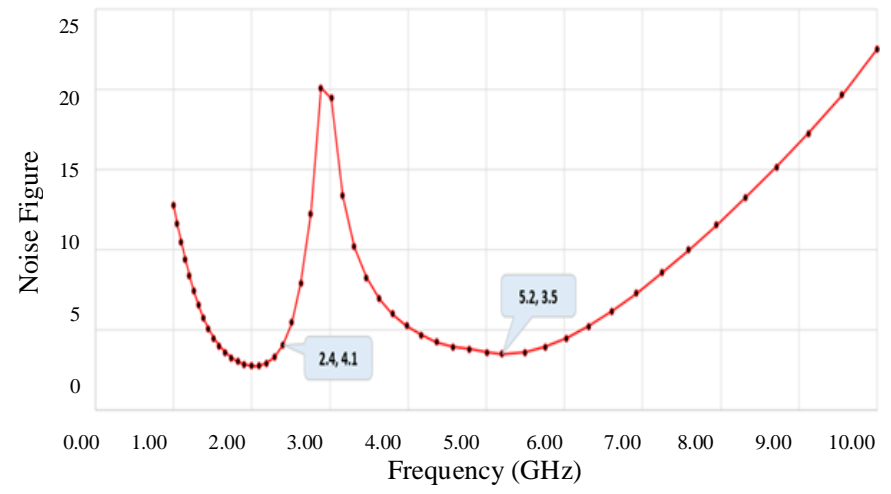

Figure 6. Noise Figure of the proposed dual band LNA 
Figure 7 shows the Smith Chart response for the input and output impedance of the proposed LNA. The result shows the impedance of $\mathrm{S} 11$ is $1.3749+\mathrm{j} 0.2585$ and $1.02+\mathrm{j} 0.0945$ at $2.4 \mathrm{GHz}$ and $5.2 \mathrm{GHz}$, respectively. Meanwhile, the impedance of S22 is $0.7317-\mathrm{j} 0.102$ and $0.7541+\mathrm{j} 0.017781$ at $2.4 \mathrm{GHz}$ and $5.2 \mathrm{GHz}$, respectively.

The simulated third-order intercept points input (IIP3) is shown in Figure 8. The two tone test has been performed for the IIP3 using a periodic steady state (PSS). The input frequency is set at $2.40 \mathrm{GHz} / 2.41$ $\mathrm{GHz}$ and $5.2 \mathrm{GHz} / 5.21 \mathrm{GHz}$ with $10 \mathrm{MHz}$ separation. As can be seen, the IIP3 of $7 \mathrm{dBm}$ and $10 \mathrm{dBm}$ at 2.4 $\mathrm{GHz}$ and $5.2 \mathrm{GHz}$ are achieved. The stability factor (K-factor) is large that 1 as shown in Figure 9. The proposed LNA is unconditionally stable across the frequency of $1.5 \mathrm{GHz}$ to $6.0 \mathrm{GHz}$.

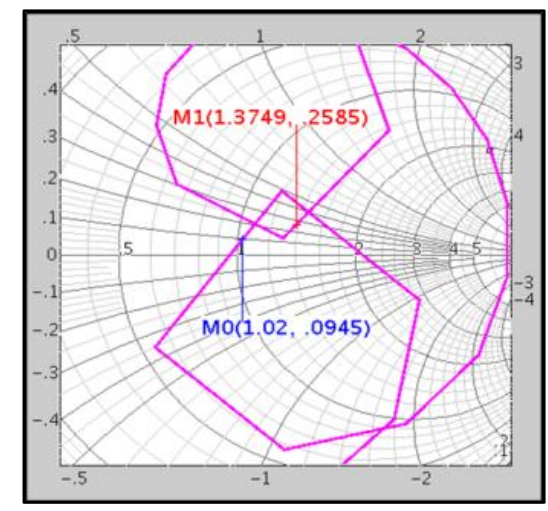

(a)

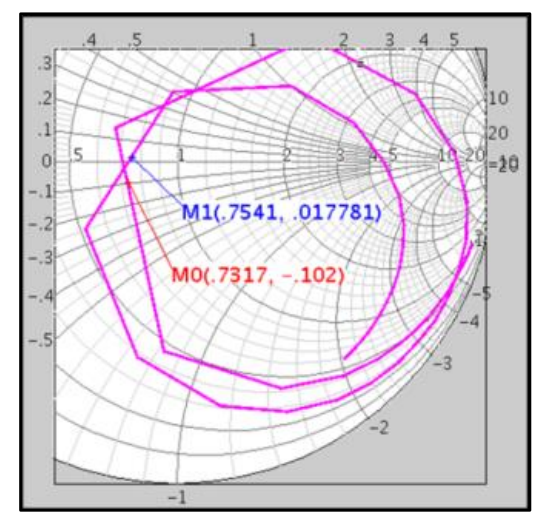

(b)

Figure 7. Smith chart response of the proposed LNA: (a) input impedance (S11), (b) output impedance (S22)

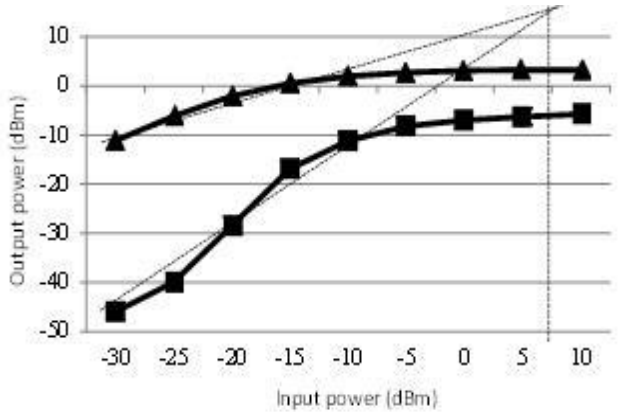

(a)

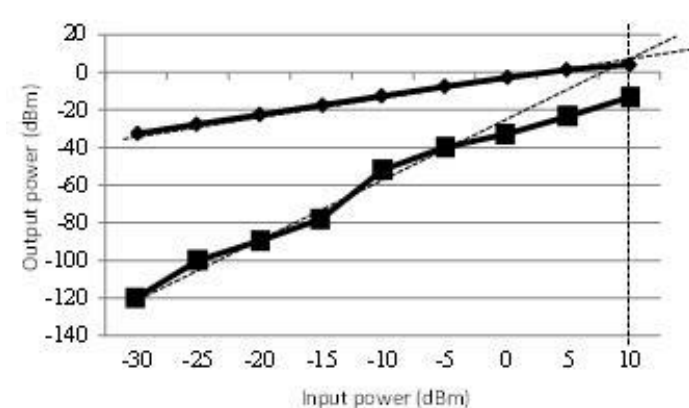

(b)

Figure 8. IIP3 of the proposed dual-band LNA (a) $2.4 \mathrm{GHz}$, (b) $5.2 \mathrm{GHz}$

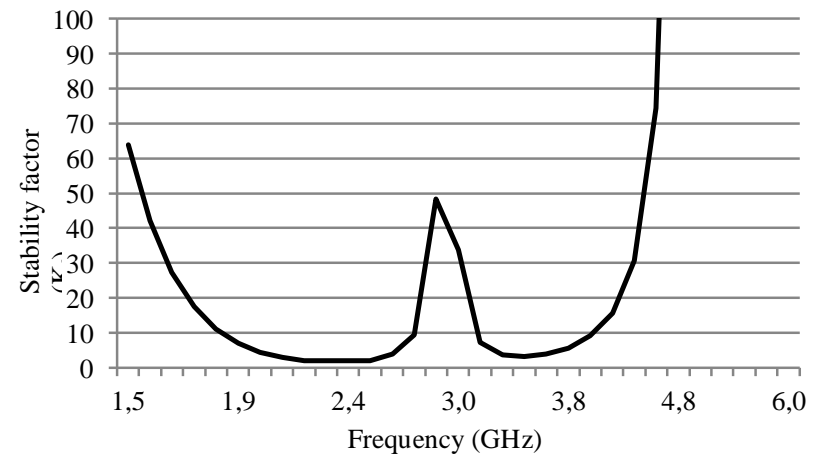

Figure 9. Stability factor (K-factor) of the proposed LNA 
Finally, the layout of the proposed dual-band LNA in CMOS $0.13-\mu \mathrm{m}$ process is presented in Figure 10. The die area including the pads is $1.69 \mathrm{~mm}^{2}$. This process has 1-poly and 6-metal layers. The layout is drawn using Virtuoso Layout Editing of Cadence. In the layout, a high metal level (Metal 6) is used for all signal paths for low losses. The signal paths of RF input and output are kept as short as possible between stages to minimize the parasitic effect. Meanwhile, a lower metal level (Metal 1) is used as a ground plane. The input and output pads are arranged in the ground-signal-ground (G-S-G) with the spacing of $100 \mu \mathrm{m}$ between pads.

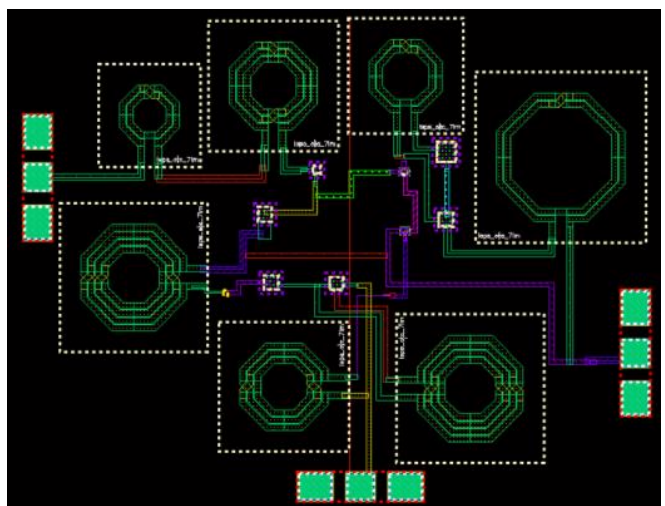

Figure 10. Layout of the proposed LNA in CMOS $0.13-\mu \mathrm{m}$ technology

Table 2 shows the comparison of performances between the previously published dual-band LNAs and this work. In [12], inductance degenerated cascode structure based on power constrained technique is proposed. A low forward gain is obtained similar with the proposed LNA in [13]. The switched external capacitor is added to the gate-source node of the input transistor to obtain input matching at $2.4 / 5.2 \mathrm{GHz}$ is presented in [14]. A low gain and moderate input return loss S11 is achieved. In [16], a cascode common source inductive degeneration is proposed with low IIP3.

The proposed LNA in this work obtains high gain and high linearity with the other parameters is comparable. However, the power consumption is slightly high due to large gain has been targeted.

Table 1. Component Parameters for Concurrent Dual-Band 2.4/5.2 GHz LNA

\begin{tabular}{lcccccc}
\hline Parameter & {$[12]$} & {$[13]$} & {$[14]$} & {$[15]$} & {$[16]$} & This work \\
\hline Technology $(\mu \mathrm{m})$ & 0.18 & 0.13 & 0.18 & 0.18 & 0.13 & 0.13 \\
Supply voltage $(\mathrm{V})$ & 1.8 & 1.2 & 1.0 & 1.0 & 1.2 & 1.2 \\
Frequency $(\mathrm{Hz})$ & $2.6 / 5.2$ & $2.4 / 6.0$ & $2.4 / 5.2$ & $2.4 / 5.2$ & $2.4 / 5.2$ & $2.4 / 5.2$ \\
S21 $(\mathrm{dB})$ & $15 / 9.5$ & $9.4 / 18.9$ & $10.4 / 11.0$ & $12.9 / 8.9$ & $19.3 / 17.5$ & $21.8 / 14.2$ \\
S11 $(\mathrm{dB})$ & $-20 /-22$ & $-12.6 /-21.0$ & $-10 /-10$ & $-13.1 /-10.5$ & $-16.8 /-19.4$ & $-18 /-16$ \\
NF $(\mathrm{dB})$ & $0.65 / 0.78$ & $2.8 / 3.8$ & $3.2 / 3.5$ & $3.7 / 3.7$ & $3.2 / 3.3$ & $4.1 / 5.0$ \\
IIP3 $(\mathrm{dBm})$ & $0.07 / 7.04$ & $-4.2 /-5.6$ & $-2.9 /-3.1$ & $-4 /-1$ & $-20.1 /-18.1$ & $7 / 10$ \\
Power $(\mathrm{mW})$ & 3.6 & 2.79 & 2.3 & 7.6 & 2.4 & 32.9 \\
Chip size $\left(\mathrm{mm}^{2}\right)$ & N/A & 0.61 & N/A & 0.9 & N/A & 1.69 \\
\hline
\end{tabular}

\section{CONCLUSION}

A concurrent dual-band CMOS LNA at operating frequency of $2.4 \mathrm{GHz}$ and $5.2 \mathrm{GHz}$ for WLAN applications is presented. The proposed LNA employed cascode common source to obtain high gain using $0.13-\mu \mathrm{m}$ CMOS technology is successfully designed and simulated. The LC network band-pass and bandstop notch filter at the input and output stages help to shape the frequency response at $2.4 \mathrm{GHz}$ and5.2 GHz, respectively. The simulation results indicate that the proposed LNA achieves the highest forward gain and input third-order intercept points among the previously published concurrent dual-band CMOS LNAs.

\section{ACKNOWLEDGEMENTS}

Author would like to express his special thanks to the the School of Microelectronic Engineering and the Department of Electronic Engineering, Faculty of Engineering Technology, Universiti Malaysia Perlis, which helped a lot to complete this project. 


\section{REFERENCES}

[1] A. Azizan,et al., "A review of LNA topologies for wireless applications," in $2^{\text {nd }}$ IEEE International Conference on Electronic Design (ICED), pp. 320-324, 2014.

[2] Jafarnejad, Roya, et al. "A low power low noise amplifier employing negative feedback and current reuse techniques." in Microelectronics Journal, vol. 49, pp. 49-56, 2016.

[3] Kitano, Taishi, et al. "A CMOS LNA equipped with concurrent dual-band matching networks." in IEEE Asia Pacific Microwave Conference (APMC), 2017.

[4] A. Azizan, et al., "Design of a $2.4 \mathrm{GHz}$ CMOS LNA using two-stage forward body bias technique for WSN application," in IEEE Student Conference on Research and Development (SCOReD), pp. 415-417, 2015.

[5] S. Arshad, et al., "Wideband and multiband CMOS LNAs: State-of-the-art and future prospects," in Microelectronics Journal, vol. 44, no. 9, pp. 774-786, 2013.

[6] Y. Shen, et al., "A dual-band CMOS low noise amplifier for wireless communication," in IET International Communication Conference on Wireless Mobile and Computing (CCWMC 2011), pp. 461-464, 2011.

[7] Kitano, Taishi, et al. "A CMOS LNA equipped with concurrent dual-band matching networks." in IEEE Asia Pacific Microwave Conference (APMC), 2017.

[8] Azizan, Anishaziela, and Sohiful Anuar Zainol Murad. "A 0.3 mW 2.4 Ghz Low Power Low Noise Amplifier Using Forward Body Bias Technique For Wireless Sensor," in Journal Teknologi, vol. 78, no. 1, pp. 31-37, 2016.

[9] Meghdadi, Masoud, Milad Piri, and Ali Medi. "A Highly Linear Dual-Gain CMOS Low-Noise Amplifier for XBand." In IEEE Transactions on Circuits and Systems II: Express Briefs 65.11 (2018): 1604-1608.

[10] Maizan Muhamad, Norhayati Soin, Harikrishnan Ramiah, "Linearity improvement of differential CMOS low noise amplifier", in Indonesia Journal of Electrical Engineering and Computer Science, vol 14, no. 1, april 2019, pp. 407-412.

[11] S.A.Z Murad, et al., "A $2.4 \mathrm{GHz} 0.18-\mu \mathrm{m}$ CMOS class E single-ended power amplifier without spiral inductors," in 2010 10th Topical Meeting on Silicon Monolithic Integrated Circuits in RF Systems, SiRF 2010 - Digest of Papers 5422842, pp. 25-28, 2010.

[12] G. Zhiqiang, et al., "The design of dual-band CMOS low noise amplifier for wireless applications," in IEEE Academic International Symposium on Optoelectronics and Microelectronics Technology (AISOMT), pp. 344-347, 2011.

[13] N.M. Neihart, J. Brown \& X. Yu, "A dual-band 2.45/6 GHz CMOS LNA utilizing a dual-resonant transformerbased matching network," in IEEE Transaction on Circuits and Systems I: Regular Papers, vol. 59, no. 8, pp. 1743-1751, 2012.

[14] Omid Eslamifar and Shirazi Reza Saraf, "Design a dual-band low-power CMOS low noise amplifier for use in WLAN applications", in IEEE 22 $2^{\text {nd }}$ Iranian Conference on Electrical Engineering (ICEE), pp. 101-105, 2014.

[15] Y.J. Hong, et al., "A concurrent dual-band 2.4/5.2 GHz low-noise amplifier using gain enhanced techniques," in IEEE Asia-Pacific Symposium on Electromagnetic Compatibility (APEMC), pp. 231-234, 2015.

[16] S. Sattar and T.Z.A. Zulkifli, "A 2.4/5.2-GHz Concurrent Dual-Band CMOS Low Noise Amplifier," in IEEE Access 5, pp. 21148-21156, 2017.

\section{BIOGRAPHIES OF AUTHORS}

\begin{tabular}{|l|l|}
\hline & $\begin{array}{l}\text { Sohiful Anuar Zainol Murad received the B.Eng degree in Electronic Engineering from Saga } \\
\text { University, Japan, in 2000, the Master of Science in Electronic Systems Design Engineering } \\
\text { from the Malaysia Science University, Malaysia in 2004 and PhD in electronics from Kyushu } \\
\text { University, Japan in 2011. Currently he is a senior lecturer in the School of Microelectronic } \\
\text { Engineering, Universiti Malaysia Perlis, Malaysia. His research interests include electronic } \\
\text { circuits design, analog and radio frequency integrated circuit design. He has over } 80 \text { publications } \\
\text { including journals and proceedings published in SCOPUS and five academic books. }\end{array}$ \\
\hline & $\begin{array}{l}\text { Ahmad Fariz Hasan received the B Eng. degree in Electrical Engineering (Telecommunication) } \\
\text { from Universiti Teknologi Malaysia, in 2007. From 2007 till 2010 he serve as Process and } \\
\text { Equipment engineer at Intel Malaysia. He then obtained his M.Eng in 2012 in Electrical } \\
\text { Engineering at Universiti Teknologi Malaysia. He is currently pursuing his Phd. in Electronic } \\
\text { Engineering at the School of Microelectronic Engineering, Universiti Malaysia Perlis. } \\
\text { His research interest includes the areas of design of CMOS Power Amplifier, Radio Ferquency } \\
\text { Integrated Circuit, Internet of Things, VLSI Design, and Radio Frequency for millimeter wave } \\
\text { application. He has published many conference proceedings as well as journal papers in local } \\
\text { and international journals. }\end{array}$ \\
\hline
\end{tabular}




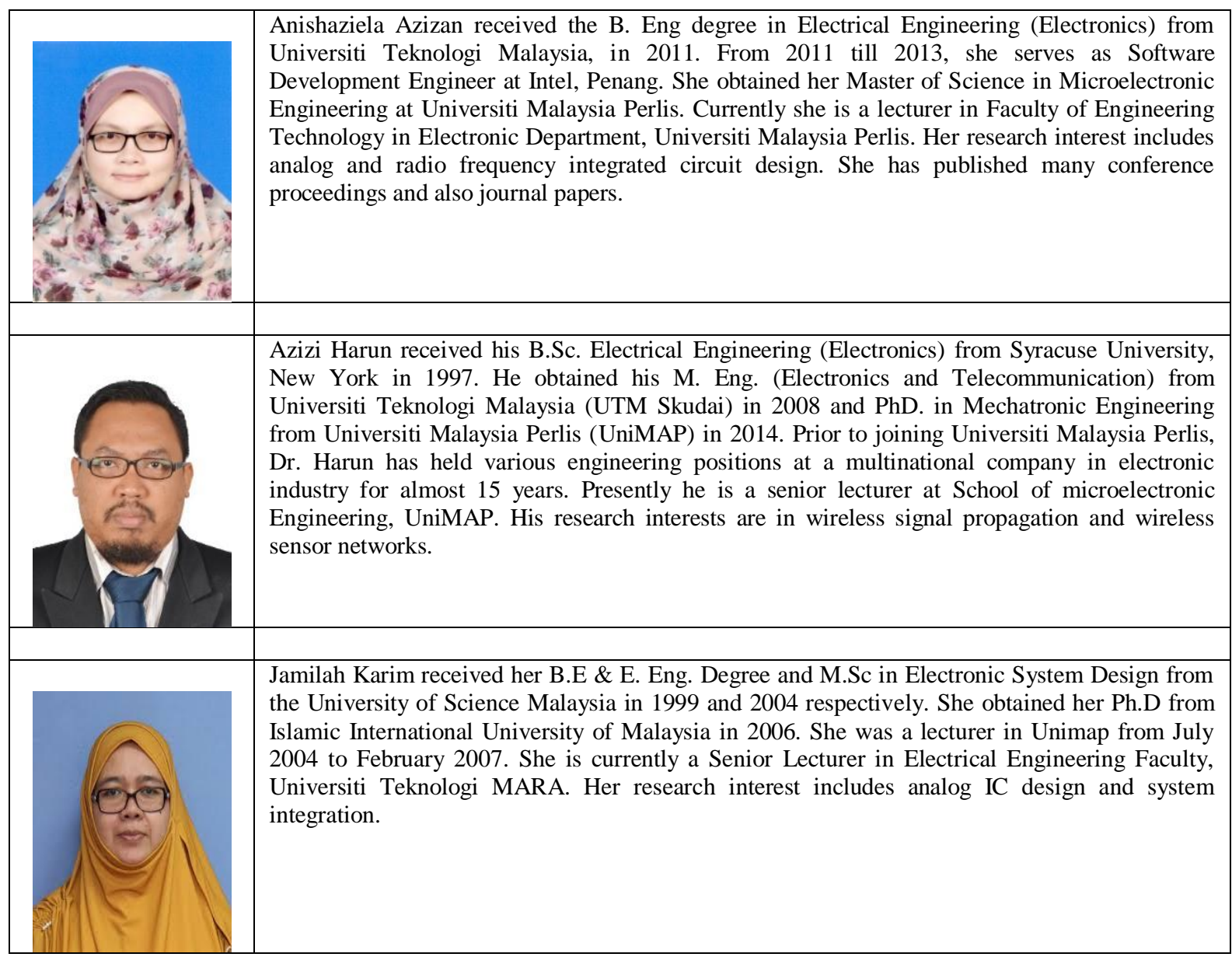

